\title{
26 The place of informal workers in different approaches to social protection
}

\author{
Francie Lund
}

\section{Introduction}

Social protection arises in response to different concerns of different nation states. Social protection for workers, in the form of access to social insurance, appeared as a feature of industrialised nations in the nineteenth century. In Germany, in 1889, Chancellor Otto von Bismarck introduced the first measure of social security focused on the workforce - specifically, formal workers. Social security, as it became known, spread rapidly through Europe. In Britain, an organised national programme of school meals appeared in the early twentieth century as a response to the poor nutritional state of men presenting themselves to fight in the imperialist Anglo-Boer War in South Africa. In the USA, the Great Depression triggered the shift in economic policy towards massive investment in infrastructural and economic programmes, such as the Tennessee Valley Authority, as well as initiating a national old age pension system. In Britain, the introduction of Beveridge's plan for a welfare state was blocked by Churchill before the Second World War; it was accepted following the war and developed into Britain's comprehensive welfare state that included the social insurancebased national health system.

The core debate in social protection is about the relationships between, and respective responsibilities of, the state, the market, and individuals, with a core concern being the extent to which state intervention distorts markets and undermines the "self-reliance" of families and communities. This relates also to whether the objective of social protection is to address and mitigate poverty or also to play a redistributive role.

Welfare regimes in the Global North were largely built on assumptions of (nearly) full employment in formal work. It was assumed that workers and their families could be protected through contributory social benefits, with a residual set of social assistance benefits for the very poor or those unable to enter formal labour markets.

Inexorably, increasing numbers of workers across the world are experiencing the erosion of their social protection. Informal workers, by definition, do not receive work-related social protection, though some, in some countries, do receive social benefits as citizens. The processes of casualisation of employment 
mean that growing numbers of workers, though they may have steady employment, nevertheless have some work-related benefits capped, stopped, or never awarded at all.

One of the barriers to the development of appropriate and equitable economic and social policies is this: those who "do" social policy do not see informal workers - they see citizens, or "poor and vulnerable and marginalised" people. Those who "do" economic policy - macro and micro - do not see labour as a "produced factor of production" and, therefore, do not see social spending as investment in the reproduction of society - and of the labour force - of the present and future.

\section{Getting social protection for informal workers on the map}

When the WIEGO (Women in Informal Employment: Globalizing and Organizing) Social Protection programme was started in 2000, there was very little published work on social protection for informal workers. A singular exception was the ILO book, Social Security for the Excluded Majority (Von Ginnekin 1999), which explicitly foregrounded informal workers Three years later an edited volume commissioned and published by the Friedrich Ebert Stiftung assessed social protection systems in nine countries in South-east and East Asia (Adam, von Hauff, and Marei 2002); all chapters noted the absence of provision for informal workers. Elsewhere, some literature and case studies emerged on related topics such as micro insurance, micro savings, rotating credit associations by/for informal workers and some publications by the Self-Employed Women's Association (SEWA) of India on their health insurance scheme and childcare services.

One of the first activities of the WIEGO Social Protection programme was a book for ILO's STEP (Strategies and Tools against Social Exclusion and Poverty) programme on a gendered approach to social protection for informal workers (Lund and Srinivas 2000); this publication purposely moved away from the "poor and marginal and excluded" paradigm towards seeing the informally employed as workers. The core question framed by WIEGO in this volume was: "Under what conditions can what kind of workers in the informal economy (and especially poorer women) get access to what core measures of provision, which can be incrementally improved upon in the future?" (ibid.).

In 2002, WIEGO's Social Protection Programme produced a framework paper for its work. Key characteristics of the conceptual and strategic approach outlined in that framework paper were:

- It recognises the right to social protection as an inalienable part of work.

- It has as a core variable the different status in employment, along a continuum from wholly formal employment, to informal employment, with many gradations in between.

- It focuses on poorer women, but not to the exclusion of men.

- It keeps open a role in social protection for all interest groups.

- It advocates principles of equity and redistribution (Lund 2004: 238). ${ }^{1}$ 
A point of departure was that the strategic approach had to be incremental. It did not expect that fundamental differences in worker benefits would be possible in the short term, but that fundamental differences would be the longer-term goal. As in the book for ILO STEP, the WIEGO framework paper advocated a multidimensional approach to understanding risk and protection, integrating a lifecycle approach, an analysis of work-related risks based on occupational sector and place of work, and a commitment to informal worker involvement in policy processes and reforms.

I first presented the framework paper at a 2002 conference of the InterAmerican Development Bank in Santiago, Chile, at which Armando Barrientos also presented a paper on women in the informal economy in Latin America (Barrientos 2004). Between 2002 and 2005, WIEGO tested the approach outlined in the framework paper in a series of country dialogues and research meetings, in five Latin American and eight Asian countries. During this time, relationships were forged with organisations of informal workers and supportive NGOs, through the process facilitated in Latin America by Carmen Roca, WIEGO's regional coordinator for Latin America and the Caribbean, and in Asia by HomeNet Thailand.

The launch of the ILO STEP/WIEGO book (Lund and Srinivas 2000) led to a further collaboration between ILO STEP and WIEGO. The partners organised a technical consultative workshop with the World Bank. The aim was to hold up an empirical mirror, as it were, against which to assess the ability of the social protection approach of each of the three organisations to integrate informal workers. Two case studies were commissioned to interrogate whether and how informal workers gained access to social protection: one of horticulture workers in Chile and South Africa (by Armando Barrientos and Stephanie Ware Barrientos); the other of garment workers in the Philippines and Thailand (by Donna Doane, Rosalinda Ofreneo and Daonoi Srikajon). As far as we know, this was the first time that social protection for informal and formal workers was analysed using global value chain (GVC) analysis.

Shortly before the workshop, the World Bank had introduced a "new approach" of Social Risk Management (SRM), which was meant to replace its short-term social safety net approach (Holzmann and Jorgenson 1999). During the workshop between the International Labour Organization (ILO), the World Bank and WIEGO, attended by HomeNet Thailand and SEWA among others, the weaknesses in the SRM approach became apparent: notably, that the poor were seen as responsible for their own social protection, and informal workers were not included in the model. It was a remarkable opportunity for the partners to come to grips, at a deep level, with the differences in our approaches, drawing on the concrete realities of informal workers' lives. After the workshop, the ILO, WIEGO and World Bank produced a book entitled Chains of Production, Ladders of Protection which presented the GVC framework, the case studies, and the lessons learned (Lund and Nicholson 2003).

Since then, the WIEGO Social Protection programme has evolved in significant ways to include a focus on occupational health and safety and on childcare 
as core components of social protection; to engage with global debates on universal health, including issues of financing, costing, and delivery systems; and to explore whether and how to engage in issues relating to social protection for elderly informal workers. What follows are selected conceptual and strategic issues that have emerged during the first two decades of WIEGO's Social Protection programme.

\section{Selected policy issues}

In the last 20 years, there have been major changes in the social protection arena, having to do with the changing role of the state, the need for protection against the risks associated with climate change and migration and the role of civil society organisations, among other things.

While there has been withdrawal in many states from social spending, along with privatisation of some services, there is also a great deal of new attention on cash transfers, and on universal health care/coverage. I select four issues to illustrate progress, regress and paradoxes.

\section{Social policy and social protection cannot remediate inequalities caused by economic, labour and trade policies that create inequality}

The lack of social protection for the majority of workers across the world is a disconcertingly hard reality and challenge. WIEGO advocates for greater security at work, at the same time knowing that processes such as the informalisation of once formal workers is further eroding social provision.

One vignette: in 2009, WIEGO was asked to present a keynote address to a European Commission (EC) and Organisation for Economic Cooperation and Development (OECD) joint seminar on "Employment, Social Protection and Decent Work in ACP Countries' (Africa, Caribbean and Pacific)". The EC and the OECD were in the process of encouraging numbers of ACP countries into trade agreements that would disadvantage those very countries; the model was so harsh and punitive that it was denounced by the World Bank. As noted in my back-to-office report:

This social protection round of training and seminars [being held by the EC and OECD] goes in parallel with their economic and aid policies. On the one hand, the economic policy branch of the EC is forcing trade deals on APC countries which are absolutely sure to impoverish them further; but on the other hand, the EC will try and remediate the bad economic and trade policy with this sort of "training" in decent work and social protection. It just does not make sense.

\section{National and local levels of government}

International organisations work chiefly with the nation state as their point of entry, and this is the level at which partnerships are typically formed and dealt 
with (World Trade Organization, World Health Organization, International Labour Organization, UN agencies, etc.). In many countries, social policy and social protection are developed at the national level. As early as the Social Protection framework paper, and then made even more clear through WIEGO's occupational health and safety project and health work more generally, is the fact that the local, municipal level of government influences the daily lives of informal workers most directly, especially with regard to the provision of infrastructure that will allow workers to access safer and healthier workplaces, including their own homes (Lund 2012). WIEGO's strategic interventions, guided by its theory of change, demand that we balance support for organisations of informal workers on the ground, with an analysis of the hierarchy in the vertical ladder between local and state or federal levels of government, and the horizontal links at the local level between different functions within local government, as well as within central government. The intersection between social protection and urban policies is an area that will be developed in the next phase of work. It is an exciting place to be, conceptually, and in terms of identifying practical spaces for policy reform.

\section{Universal health coverage (UHC) and private insurance}

The last ten years or so have seen the growth, globally, of a commitment to universal health care, or universal health coverage, endorsed and supported by significant philanthropic foundations, such as the Bill and Melinda Gates Foundation and the Rockefeller Foundation. The last great push towards universal health care (UHC) following the Alma Ata Conference in 1978, was based on primary health care (PHC); the understanding was that the $\mathrm{PHC}$ component would be state-provided. Now, in the current fervour of support for UHC, the focus is less on public health care and more on health insurance, with many promoters seeing a role for the private insurance firms supported by government. Others make the case for different roles that can be played by the state: from provision of services to financing, enabling, and guaranteeing the provision of services by others.

There are grave concerns that health programmes underpinned by private insurance tend towards the provision of curative services, and away from any significant commitment towards preventive health services as one of the pillars of primary health care and of public health. This concern is illustrated by the design and implementation of the Rashtriya Swasthya Bima Yojana (RSBY) in India, a government scheme to provide health insurance for families below the poverty line (Jain 2012) which now forms part of Ayushman Bharat, a larger programme including primary health care.

\section{Cash transfers}

A surprising development in social protection in the last 30 years has been the rapid spread of cash transfers in Sub-Saharan Africa and Latin America. Some 
attribute the main cause of the spread of this form of provision to the success of some programmes in the Global South (Hanlon, Hulme and Barrientos 2010); others proffer the idea of south-south learning, for example, from Brazil to Ghana (Foli, Béland and Beck Fenwick 2018); others would say it was important that the World Bank's own researchers found that cash transfers, properly designed, could be effective as well as equitable, and could be seen as compensation for the damage caused by the privatisation of pensions schemes under structural adjustment. Bob Deacon writes about ILO's Social Protection Department playing a driving role (Deacon 2013); others point to the NGO HelpAge International driving the move to cash transfers for elderly people.

The WIEGO Social Protection team, and WIEGO as a whole, see the merit of cash transfers in providing direct income support, especially to women and children. The initial model of the Global Social Protection Floor (SPF) comprised essentially cash transfers over the life-cycle, as well as affordable basic health care. Early SPF documents acknowledged informal workers but clubbed them with "the unemployed". In the course of the acceptance by all UN agencies of the SPFs, and the start of implementation, the focus on informal workers is being further diluted. The intended "universality" of the SPFs might be - probably is contributing to the loss of focus on worker-oriented social protection in favour of citizen-based social protection (see Laura Alfers, Chapter 27 in this volume).

\section{Going forward}

Social protection for informal workers is now on the global policy map. Strong partnerships between WIEGO, some local and national actors as well as international organisations and other NGOs have contributed to this. The processes of working through existing organisations of informal workers wherever possible was a unique and effective way of bridging between organisations of workers, on the one hand, and the authorities or agencies who control their spaces, on the other.

Policy research and advocacy on women's informal work and childcare underscore the challenges of making visible all the ways that family care impacts the experiences of informal women workers. Participatory action research and regional meetings that were part of WIEGO's Child Care Initiative revealed that poorer informal working women themselves do not necessarily articulate childcare as a priority need. Key organisational and programme leaders have suggested that this might be due to the fact that the workers themselves see childcare as something that simply is women's personal responsibility not that of others or society at large.

The boundary between paid work by adults and unpaid domestic chores, care work and reproductive labour is difficult to maintain when advocating for social protection, particularly family-related benefits, for women informal workers. Diane Elson notes the invisibility of unpaid care work, and how social reproduction is taken for granted. She notes that "[the] unpaid care economy is outside the production boundary, but its operation has implications for what goes on 
inside the production boundary" (Elson 2004: 65). So much of unpaid work necessary to the household is performed by women that it affects their ability to engage in paid work outside of, or even within, the home. Women with children engage in the lower earning, least predictable forms of informal work as a result of care responsibilities.

Nevertheless, practical interventions have shown that women do engage with specific work-related issues when the connection of these issues to their daily work experience is direct and clear. For example, as part of WIEGO projects aiming to improve awareness and practices of occupational health and safety in Warwick Junction in Durban, South Africa, information campaigns and training undertaken "reinforced to traders that they are workers, that the spaces in which they work are workplaces, and that they have rights and responsibilities in relation to that space" (Alfers et al. 2016).

Going forward, a challenge for policy-relevant research and advocacy for social protection is how to maintain the focus on improving paid work, and consider the boundary in women's lives between unpaid care work roles and earning activities, while interacting intellectually and strategically with a broad array of international and national organisations and NGOs. Some of these work in different but closely related domains and may address only women's household responsibilities, on the one hand, or only consider men's needs when dealing with workers' social protection, on the other.

A related challenge, detailed by Laura Alfers in Chapter 27, is how to approach social protection through both a citizenship and work status lens, encompassing consideration of universal approaches to social protection provision yet ensuring consideration of the particular features of informal work that lead to specific needs of workers. A significant aspect to consider in universal approaches is the substantial need for financing support ensuring access to social protection for informal workers but also others in similarly tenuous financial situations. As Silke Staab in Chapter 28 in this volume concludes, universal systems that are built through on-going support from broad-based constituencies can be sustainable financially and politically and, in turn, ensure that all workers, informal workers among them, are included.

\section{Note}

1 The social protection framework had its roots in a study done with Smita Srinivas for the ILO initiative "Strategies and Tools against Social Exclusion and Poverty" (Lund and Srinivas 2000). 